CORRESPONDENCE

\section{Cerebral symptoms from mobile telephones}

EDITOR-Disturbing symptoms from the use of mobile telephones are being increasingly reported and have been described by Hocking. ${ }^{1}$ One of us (RAFC) has also collected a series of such cases but has not published them to date.

Many of these cases are characterised by symptoms of dizziness, disorientation, nausea, headache, and transient confusion. Such symptoms might be expected to arise from unilateral stimulation of the vestibular apparatus. This could occur from the direct action of the radiowaves on the endolymph or the hair cells in the semicircular canals or from convection currents set up in the external auditory meatus from the heat of the mobile phone. Most patients complain of a sensation of heating round the ear, often accompanied by reddening of the skin. Blanks et al have shown that there is significant variability in the precise orientation of the semicircular canals, which may result in a predilection to greater thermal stimulation in some people. Because mobile telephones tend to be used in noisy situations, the user holds the instrument much more tightly to the ear than he does a normal phone.

In our opinion there is good theoretical and clinical evidence to support the hypothesis that some people, perhaps $5 \%$ to $8 \%$ of mobile phone users, have transient symptoms of vestibular disturbance associated with their use. We think that the hypothesis should be tested experimentally as the number of people affected will increase as use of mobile phones increases. It is also important to confirm our hypothesis experimentally to find the mechanism underlying vague symptoms of disorientation and to emphasise that these symptoms do not indicate any greater risk of developing brain cancer, whether or not mobile phones are ultimately shown to have any association with cerebral tumours.

The research required is relatively simple and we would suggest that, in the light of widespread public concern, this work should be included in any programme which is proposed to clarify the issues about safety of mobile telephones.

R A F COX

Consultant Occupational Physician, Linden House, Long Lane, Fowlmere, Cambridgeshire, SG8 7TG, UK

LINDA M LUXON

Department of Audiological Medicine, Institute of Laryngology and Otology, 330-333 Grays Inn Road, London WC1X 8EE, UK

Correspondence to: Dr R A F Cox rafcox@lineone.net

1 Hocking B. Symptoms associated with mobile phone use. Occup Med 1998;48:357-60.

2 Blanks RHI, Curthoys IS, Markham CH.

Planar relationships of the semicircular canals in man. Acta Otolaryngologica 1995;80:185-96.

\section{BOOK REVIEWS}

If you wish to order, or require further information regarding the titles reviewed here, please write or telephone the BMJ Bookshop, PO Box 295, London WX1H 9TE. Tel: 020 7383 6244. Fax: 0207383 6662. Payment can be made by cheque in sterling drawn on a UK bank, or by credit card (MasterCard, VISA, or American Express) stating card number, expiry data, and your full name. (The price and availability are occasionally subject to revision by the Publishers.)

Work-related musculoskeletal disorders: report, workshop summary, and workshop papers. Edited by: STEERING COMMITTEE FOR THE WORKSHOP ON WORK-RELATED MUSCULOSKELETAL INJURIES, AND the NATIONAL RESEARCH COUNCIL. (Pp 229; £33.95) 1999. Washington, DC: National Academy Press. ISBN 0-309-06397-3.

In August 1998 a 2 day workshop was held under the auspices of the United States National Research Council (NRC) to examine the research base on work related musculoskeletal disorders, and this was later followed by some deliberations of the steering committee. The report of the steering committee and the proceedings and scientific papers from the workshop are presented in this monograph.

The NRC workshop, which was attended by leading scientists from the fields of orthopaedic surgery, occupational medicine, public health, and human factors deliberated over several major topics: the biological responses of muscles, tendons, and nerves to biomechanical stressors; the biomechanics of work stressors; the epidemiology of physical factors; non-biomechanical (psychosocial) factors that might affect the musculoskeletal system; and possible risk mitigating interventions. Under each topic there were commissioned presentations, which are reproduced fully in this monograph, together with some written and oral responses and a considered overview.

The committee's efforts were focused in particular towards answering seven specific questions posed by Congressman Robert Livingston. These concerned the identity, diagnosis, and classification of such disorders, their causes, incidence, and prevention, and the major areas of research uncertainty. (Needless to say, not all of the questions could be answered confidently!)

In reviewing this book, I could not help reflecting on the role of workshop proceedings and who might wish to buy such a summary; also, whether the book represented an important advance on existing major competition-such as the comprehensive critical review by NISOH, or the detailed Work-related musculoskeletal disorders: a reference book for prevention, published by Taylor and Francis. The proceedings of meetings can be a mixed feast, with tasty new morsels, meaty dishes, and stale fare served up together. The best of offerings have the following recipe: one conscientious editor, a peer review process, and a liberal helping of original research papers, written up as formally and thoroughly as they would be when freely submitted to a journal in open competition. The compilation that occupies the second half of this book does not match this recipe, but does represent a series of interesting reviews and synopses in important areas of research interest.

Of course the scope of the book is broader in seeking to distil and summarise, rather than to break new ground, and in this respect it partially succeeds. But the advance is a fairly small one. Those with an interest in work related musculoskeletal disorders will want to read this book, but perhaps not to possess it. One section which is likely to be of particular interest to them, concerns invited experts' views on the adequacy and limits of the NISOH review already mentioned, which, paradoxically, represents a more essential addition to the occupational physician's library.

KEITH PALMER

Occupational musculoskeletal disorders, second edition Edited by: NORTIN M HADLER, JOYCE-RACHEL JOHN, MICHELLE LAPLANTE. (Pp 433; \$75.00) 1999. Philadelphia, PA: Lippincott Williams and Wilkins. ISBN 0-7817-1495-8.

The preface to this book indicates that its intended readership includes practising occupational physicians and nurses, specialists in musculoskeletal disease, family practitioners, and members of the health insurance industry. But to some extent its content belies the stated target. This is not a practical primer, nor a scholarly and dispassionate review of the relation between work and musculoskeletal disease. Instead it is a very honest, brave, and personal view of how the author thinks such diseases arise in the main from illness behaviour and illness labelling.

Their basic tenet is that musculoskeletal symptoms are ubiquitous and generally benign, but can become incapacitating as the patient and the physician seek a medical explanation and supply a diagnostic label. They also seeks to dispute much received medical wisdom, the evidential basis of which they dispute. Chapter headings such as "the dangers of the diagnostic process", "iatrogenic labelling as in the fibromyalgia paralogism", "the disabled, the disallowed, the disaffected, and the disavowed" and "hand-arm vibration syndrome: a revisionist historiography" reflect these twin viewpoints, which give rise to passages such as: "..Raynaud's phenomenon denotes a personality trait; it's not a disorder", and headings such as "carpal tunnel syndrome is not a cumulative trauma disorder". This eclectic book is striking in the enthusiasm with which it embraces the psychosocial model of musculoskeletal illness and disparages the mechanical-biological model. It is well referenced and informative, with critiques that are both energetic and relentless, but ultimately the authors' stance of unashamed bias colours the whole.

This is a pity. Many of the ideas expressed on causation are compatible with widely held views of illness behaviour (although forcibly expressed). There are also interesting and potentially useful chapters on workers' compensation schemes and coping with arm pain in the workplace.

But lack of balance is not the book's only shortcoming. Given its title, there are also several surprising omissions. For example, 
the clinical chapters (on the neck, back, upper limb, and lower limb) provide little information on putative occupational risk factors and the epidemiological evidence surrounding these. As befits a textbook which reflects the American care model in occupational health, there are passages on therapeuticssuch as the side effects of salicylates - and information on homeopathy, osteopathy, and chiropractice; but the bias is towards the clinical rather than the occupational health management of musculoskeletal disorders, and this too was something of a surprise and a disappointment. Fitness for work and its assessment is not considered in a meaningful way.

The question is whether the good outweighs the bad. You pay your money and take your choice: if you want a healthy dose of scepticism, this is the place to look; however, there is a danger you may receive an overdose, and if you prefer a balanced or more dispassionate account you should look elsewhere.

KEITH PALMER

Air pollution and health. Edited by: STEPHEN $T$ HOLGATE, JONATHAN M SAMET, HILLEL S KOREN, ROBERT L MAYNARD. (Pp 1065; £79.95) 1999. San Diego and London: Academic Press. ISBN 0-12-353225-4.

Among the most serious dangers to public health is air pollution. It is at least as important as cancer and vascular disease as a cause of death, illness, and lost human potential, it is a major source of environmental damage, and it seems to be an inescapable accompaniment of industrial progress. In the 19th century we measured a country's power by its production of sulphuric acid, perhaps we should now do so by the acid particles breathed by its citizens? After the very obvious air borne disasters of the 1950s due to fogs in Britain, Mexico, and the USA, there was a rapid legislative and technical response to reduce obvious sources of pollution, and then medical and scientific attention fell away until the growing menace of asthma and other respiratory diseases, coupled with our better ability to detect and measure airborne substances showed that the problems were as serious as ever, even if more subtle in their form and attack.

This book rightly claims to be the first attempt to produce a comprehensive account of the sources, mechanisms, physical behaviour, and health effects of air pollution, and of approaches to its regulation, including forays into economics, trade offs between risk and benefit, and communication about risk with the public. There are 68 authors from Europe and the Americas, all of whom are making active contributions to understanding this huge area. Considering their research interests, they have been surprisingly well marshalled by the four distinguished editors into writing up to date, readable, and informative chapters.

The general approach has been encyclopaedic as the nine major sections cover the history of air pollution, physical meteorology, atmospheric chemistry, the physical geogra- phy of air pollution related to its main sources, the measurement of personal exposure, health effects in humans and in laboratory systems, details of major chemical and particulate pollutants, the estimation of health and financial impacts and approaches to regulation including national and international setting of standards for air, and two way communication with the public. The text is accompanied by many clear diagrams and graphs, and several helpful photomicrographs, and every chapter carries many pertinent and recent (to 1998) references.

The strengths of this book are its breadth and clarity, and so its value both as a source of analysed information and conclusions, and as an entry point into the detailed research literature. I particularly appreciated the information abut meteorology, atmospheric chemistry, and surveillance and measuring strategies for the biologist, and the focused accounts of epidemiology and respiratory physiology, defences, and diseases, which should inform the physical scientist about the subtle difficulties of biology. Its weaknesses are those of any synoptic work - the reader must have some background knowledge to understand the depths of the knowledge presented, and the need for broad coverage prevents the inclusion of extensive detail. The balance seemed correct to me in most respects, as the references always pointed to original sources that could be read with appropriate cautions and criticisms in mind.

Physicians at any level, public health officials, and sanitary engineers should consult this book regularly. It will be of as much value and interest to regulators, lawyers, and industrial engineers looking into the causes and possible controls over air pollution and it will be a major source for any public group wishing to know more of the facts and do something about the aerial refuse we now breathe.

\section{ANTHONY D DAYAN}

General and Applied Toxicology, 2nd edition. By: B Ballantyne, $T$ C MARRs, $\mathrm{T}$ SYVERSEN (Pp 2199, xxvi plus 144 of separate indices; £350.00) 1999. London: MacMillan. ISBN 1-56519-242-0.

Britain has a lengthy and mixed history in the world of toxicology; some industrial and community diseases due to toxic substances have occurred and were first recognised here from the 1st century AD onwards, and our scientists have made seminal contributions to the basic understanding of toxicology. Is this major work to be the epitaph of our achievements, as academic and industrial pressures relentlessly diminish our base of working toxicologists, or is it a further pointer to our understanding of the knowledge and practice of a subject of growing public importance? And, being the second edition of a justifiably successful monograph, how well have advances been included and presentation improved?

The new preface points out the considerable extent of the new material in the book, recognising the speed of progress in molecular toxicology coming from new knowledge in basic sciences, and the wide changes in regu- latory approaches to assessing the safety of most products, food, and the environment. As a result, it has grown from two to three volumes, the extensive reference lists have been brought up to date, sometimes with the addition of focused suggestions for additional reading, and the multinational character of the list of authors has been further expanded.

The editors have served their readers well by providing a very extensive survey of the sciences and other factors that underlie toxicology as a discipline applied to the demonstration and understanding of chemical hazards and to practical control of toxic risks in the home, at work, in the clinic, and in the environment. The 116 pages of the subject index and the 38 pages of the chemical index together lead the enquirer to critical accounts of almost every topic that could be brought into toxicology, including education, studies in man, further information sources and even the coyly termed "idiopathic environmental intolerances" (multiple chemical sensitivity, and its cousins). There is particular strength in the clarity of the links made with cognate subjects, such as pharmacology, cell biology, analytical chemistry and biochemistry, immunology, and veterinary and human medicine. A major feature is the concentration on methods to recognise, study, and assess toxicity in its many guises, which leads directly to accounts of good practices in examining substances and circumstances for evidence of toxicity, and how to use that information to evaluate the risks of exposure. The book is more, much more than a list of techniques and regulations. It is also a major reference source in its own right, providing basic and practical information about the actions of many different substances, ranging from medicines to foods and air pollutants. The presentation is clear, there are many clear diagrams and tables and the authors have somehow been persuaded to write or to be edited into producing highly readable text, clear and mostly concise, even when dealing with the drier topics- such as PKPD modelling, GLP, and ICH.

The weaknesses are those that are inevitable in any multi-author work, especially the concentration on national approaches in some chapters, when international differences are better recognised in others, and the difficulty that some authors must have had of balancing personal enthusiasms against more general views that other aspects are more important.

Overall, although some can already foresee the demise of the printed book, this is a balanced and comprehensive account of what toxicology is, how to use and interpret its findings, and of its scientific and clinical base. It is equally a well presented guide to the actions of many substances selected as type examples, and to further sources of even more recent or alternative information if further data are required.

It is an effective reference source, it will be a valuable aid to teaching toxicologists, allied scientists, physicians, and those who regulate, are regulated, or who expect to be protected from toxicity. Like all monographs it belongs in libraries, but it would be no less helpful in clinics, courts, and in laboratories.

ANTHONY D DAYAN 